\title{
DO CHÂO DO SERTÃO AO CORAÇÃO DO POETA: A IDENTIDADE PIAUIENSE NA POESIA DA “LIRA SERTANEJA” DE HERMÍNIO CASTELO BRANCO
}

\author{
FROM THE FLOOR OF SERTÄO TO THE HEART OF THE POET: THE PIAUIENSE \\ IDENTITY IN THE POETRY OF "LIRA SERTANEJA” BY HERMÍNIO CASTELO BRANCO \\ EL CHON DEL SERTÓN AL CORAZÓN DEL POETA: LA IDENTIDAD PIAUIENSE EN LA \\ POESÍA DE LA “LIRA SERTANEJA” DE HERMÍNIO CASTELO BRANCO
}

\author{
Elisabeth Mary de Carvalho Baptista \\ Universidade Estadual do Piauí - UESPI \\ baptistaeli@gmal.com
}

\begin{abstract}
Resumo: Expressada pela ideia e sentimento de pertencimento a um grupo ou lugar, a identidade se formula através de diferentes formas de representaçáo ou símbolos, podendo se relacionar à história, valores, língua, folclore e lugares. A relaçáo com o lugar pode se constituir como fator de construção da identidade, pois as referências com a terra onde se nasce, se herda valores e constroem-se memórias, podem definir a essência de um grupo humano. Dentre as formas de representação desse simbolismo da identidade, a literatura permite que se registrem estórias contadas sobre lugares, memórias que conectam presente e passado e imagens construídas. Um dos elementos de construção da identidade do povo da região nordeste brasileira, encontra-se na importância dada ao espaço geográfico do sertão. $\mathrm{Na}$ literatura piauiense identifica-se na poesia de Hermínio Castelo Branco, em três de seus poemas da obra "Lira Sertaneja”, intitulados "Em Viagem ao Amazonas", "À Margem do Rio Negro" e "Canto do Desterrado", uma forte conotação de sua relação intrínseca com o Piauí, ensejando uma identidade para com sua terra e através dela seu desejo de que se conservassem imutáveis os cenários que amava, tanto humanos como geográficos, objeto de estudo deste artigo.
\end{abstract}

Palavras-Chave: Geografia. Literatura. Identidade. Lugar. Hermínio Castelo Branco.

\begin{abstract}
Expressed by the idea and feeling of belonging to a group or place, the identity is formulated through different forms of representation or symbols, being able to relate to history, values, language, folklore and places. The relation with the place can be constituted as a factor of construction of the identity, because the references with the land where one is born, one inherits values and constructs memories, can define the essence of a human group. Among the forms of representation of this symbolism of identity, literature allows to record stories told about places, memories that connect present and past and constructed images. One of the elements of construction of the identity of the people of
\end{abstract}


the northeast Brazilian region, is in the importance given to the geographic space of the sertáo. In the literature of Piauí it is identified in the poetry of Hermínio Castelo Branco, in three of his poems of the work "Lira Sertaneja", titled "Em Viagem ao Amazonas", "À Margem do Rio Negro" and "Canto do Desterrado", a strong connotation of its intrinsic relation with Piauí, giving an identity to his land and through it his desire that the scenarios he loved, both human and geographic should remain unchanged, object of study of this article,

Keywords: Geography. Literature. Identity. Place. Hermínio Castelo Branco.

Resumen: Expresada por la idea y el sentimiento de pertenencia a un grupo o lugar, la identidad se formula a través de diferentes formas de representación os símbolos, pudiendo relacionarse con la historia, los valores, la lengua, el folclore y los lugares. La relación con el lugar puede constituirse como factor de construcción de la identidad, pues las referencias con la tierra donde se nace, si hereda valores y se construyen memorias, pueden definir la esencia de un grupo humano. Entre las formas de representación de ese simbolismo de la identidad, la literatura permite que se registren historias contadas sobre lugares, memorias que conectan presente y pasado e imágenes construidas. Uno de los elementos de construcción de la identidad del pueblo de la región nordeste brasileńa, se encuentra en la importancia dada al espacio geográfico del sertáo. En la literatura piauiense se identifica en la poesía de Hermínio Castelo Branco, en tres de sus poemas de la obra "Lira Sertaneja”, titulados "Em Viagem ao Amazonas", "À Margem do Rio Negro" y "Canto do Desterrado", una fuerte connotación de su relación intrínseca con Piauí, con una identidad para con su tierra ya través de ella su deseo de que se conservaran inmutable los escenarios que amaba, tanto humanos como geográficos, objeto de estudio de este artículo.

Palabras Clave: Geografía. Literatura. Identidad. Lugar. Hermínio Castelo Branco.

\section{INTRODUÇÃO}

Questóes sobre a identidade em diferentes perspectivas tem ocupado significativo espaço em estudos e debates acadêmicos e científicos considerando uma premente necessidade de afirmaçáo ou autoafirmaçáo do ser humano no desenvolvimento de suas relaçóes sociais consigo mesmo e com os outros. Identidades pessoal, cultural, étnica, sexual, de gênero, espacial, territorial, regional e nacional, são construçóes que decorrem geralmente do sentimento ou afetividade que determinada pessoa elabora no sentido de se reconhecer como pertencente a um grupo cujas características físicas, psicológicas, afetivas, e até mesmo geográficas lhe são semelhantes ou aceitas como tal.

Num contexto global tão diverso e diversificado, envolvido pela globalização e pela massificação da informação, a procura das pessoas por um lugar, o "seu lugar", está sempre em evidência. A relaçáo com o lugar pode então se constituir como fator de construção de uma identidade, pois as referências com a terra onde se nasce e da qual se herda 
valores, e constroem-se memórias, podem definir a essência de um grupo humano ou de um indivíduo. Esta constante busca se faz pronunciar através das diferentes formas de manifestações da cultura humana, como a música, o cinema, a religião, o folclore e a literatura. Esta última possibilita o registro de estórias contadas sobre lugares, memórias que conectam presente e passado, e imagens construídas de espaços numa dimensão local, regional ou até de uma nação. Através da poesia, uma de suas modalidades que mais representa as emoçóes e afliçóes humanas a literatura consegue externalizar sentimentos, sentidos e impressóes da alma e coração dos seres humanos sobre suas vidas, suas relações sociais e com o próprio espaço onde vivem.

Nesta relação a Geografia trava um diálogo saudável com a literatura, pois as obras literárias podem revelar aspectos relacionados ao meio físico bem como as formas de se viver e as características socioculturais, econômicas e históricas de uma dada área (OLANDA; ALMEIDA, 2008). No contexto da ciência geográfica a abordagem humanista cultural é a que se entrelaça com a literatura. $\mathrm{Na}$ análise das convergências entre a Geografia Cultural e a Literatura, Olanda e Almeida (2008, pp.23-24) afirmam que

Se por um lado, a Literatura reflete a realidade físico-humana por meio da dinamicidade da trama [...] por outro, a abordagem cultural na Geografia coloca a Cultura e o Homem como centro para compreender a construção do meio, repleto de significados e de processos que criam identidades.

Evidencia-se que o texto literário se apresenta como um recurso de análise para a Geografia no estudo de relaçóes identitárias com os espaços geográficos ou lugares expressos nas diferentes formas de narrativas.

Neste sentido, Almeida (2014, p.19) na apresentação da relação entre Geografia e Literatura analisa que a "[...] narrativa, romance, poesia, apreendem diferentemente o mundo: como origem, como discurso. O geógrafo, para melhor identificar este mundo sensível [...], recorre à literatura”.

No Brasil a conexão com a terra, como o chão de seus antepassados, confere aos brasileiros uma forte relaçáo de identidade presente em todo o território nacional de norte a sul. Esta relação também é presente na região Nordeste sendo fortemente representada pelo sertão, ${ }^{1}$ cujas características fisiográficas próprias conseguem estabelecer uma identidade nordestina para os que nascem e vivem ali. A força da terra imprime em seu nativo uma perspectiva de identificação que o acompanha para além das divisas territoriais.

Este artigo permeando a interface entre a Geografia e a Literatura, vis a vis da produção literária do poeta piauiense Hermínio Castelo Branco, tem como objetivo analisar sua poesia abordando a dimensão da identidade a partir do expresso principalmente em três de seus poemas da obra "Lira Sertaneja", publicadas pela primeira vez em 1881, intitulados “Em Viagem ao Amazonas”, "À Margem do Rio Negro" e "Canto do Desterrado".

1 No Nordeste, do ponto de vista geográfico, o sertão corresponde ao espaço que se estende dos estados centrais da região ao Piauí, acrescido do litoral setentrional (ANDRADE, 1998), abrangendo ainda o norte de Minas Gerais (ALMEIDA, 2010). 
A construção teórica teve como aporte a pesquisa bibliográfica e eletrônica recorrendo à contribuição de Tuan (1982, 1983), Claval (1997, 2001), Ferreira (2000), Hall (2005, 2014), Olanda e Almeida (2008), Silva (2014) entre outros autores.

$\mathrm{Na}$ interpretação das poesias optou-se por trabalhar com a análise de conteúdo, que se caracteriza pelo exame de dados linguísticos, através do qual são identificados, numerados e categorizados os elementos fundamentais da comunicação (APPOLINÁRIO, 2009). Considerada uma técnica de investigação científica, também utilizada nas Ciências Humanas e no estudo de textos literários por possibilitar inventariar a frequência com que alguns temas, palavras ou ideias são citados em um texto visando aferir o peso relativo conferido a um determinado assunto pelo seu autor (SÁ-SILVA; ALMEIDA; GUINDANI, 2009).

Neste caso, levou-se em conta a alocução empreendida pelo poeta considerando que a análise de conteúdo conforme Silva, Gobbi e Simão (2005, p.74) "aparece como uma ferramenta para a compreensão da construção de significado que os atores sociais exteriorizam no discurso", considerando-se em relação a Hermínio Castelo Branco, a compreensão de sua realidade e a interpretaçáo dos significados em seu entorno expressos em sua poesia.

\section{IDENTIDADE, ESPAÇO E LUGAR: DA ABORDAGEM CULTURAL NA NARRATIVA LITERÁRIA}

A Geografia Cultural "considera o Homem e suas experiências com o meio, vinculando espaço-lugar-cultura-significado-identidade e cotidiano como centro de sua análise" (OLANDA; ALMEIDA, 2008, p.19). Ensejada por Claval (1997, p. 89) um de seus expoentes, relaciona-se à interação dos seres humanos com a terra e a natureza, pois nesta perspectiva o autor indica que

[...] a geografia cultural está associada à experiência que os homens têm da Terra, da natureza e do ambiente, estuda a maneira pela qual eles os modelam para responder às suas necessidades, seus gostos e suas aspiraçóes e procura compreender a maneira como eles aprendem a se definir, a construir sua identidade e a se realizar.

Essa abordagem tratando do estudo do sentido, tanto global como unitário, que a sociedade proporciona à sua relação com o espaço e com a natureza (BERQUE, 1998), de acordo com Olanda e Almeida (2008, p. 20)

[...] empenha-se, ainda, em compreender o processo humano de construçâo de identidade e realização individual e coletiva [...] E, também, ao propor investigar os sentimentos, as representaçóes e as aspiraçóes humanas e, ainda, como o homem se vê e como constrói sua identidade.

Uma ênfase ao trabalho geográfico na área da geografia cultural é dada por McDowell (1996, p.159) que indica que esta abarca "desde as análises de objetos do cotidiano, representaçáo da natureza na arte e em filmes até estudos do significado de paisagens e 
a construção social de identidades baseadas em lugares [...]”. Para a autora o foco desta abordagem está direcionado também a investigar a cultura material, os costumes sociais e os significados simbólicos.

Tratando sobre a renovação temática da Geografia Cultural, Corrêa (1999, p.53) infere que a "religião, [...] percepção ambiental, [...] identidade espacial e a interpretação de textos (literatura, música, pintura e cinema) estáo entre outras temáticas que emergiram ou foram retomadas".

$\mathrm{Na}$ abordagem cultural da Geografia o lugar se apresenta então como o espaço de construção identitária como ressalta Ferreira (2000, p. 68): "O lugar seria um centro de significaçóes insubstituível para a fundação de nossa identidade como indivíduos e como membros de uma comunidade”. Claval (2001, p. 66) enfatiza que aos lugares são atribuídos muitos sentidos e que "a construção das identidades está intimamente ligada à organização territorial e à maneira como é percebida por quem é responsável por essa organizaçáo ou a experimenta”. Ou seja, este território percebido e experimentado constitui-se no lugar.

$\mathrm{Na}$ análise sobre lugar e identidade, Silva, Santos e Martins (2001, p. 2) destacam que

Lugar é a porção do espaço apropriável para a vida, que é vivido, reconhecido e cria identidade. É nele que se dá a cidadania, o quadro de mediaçôes se torna claro e a relação sujeito-objeto direta. É no lugar que ocorrem as relaçôes de consenso e conflito, dominação e resistência. É a base da reprodução da vida, da tríade cidadão-identidade-lugar, da reflexão sobre o cotidiano, onde o banal e o familiar revelam as transformaçôes do mundo e servem de referência para identificá-las e explicá-las.

Neste sentido, entende-se que a literatura pode, através de suas narrativas, demonstrar as relaçôes entre os seres humanos e o espaço, e a Geografia pode contribuir para a interpretação de textos literários que abordam específicos espaços geográficos (LIMA, ARAUJO; SALGADO, 2009) ou não.

Sendo, então, pertinente o diálogo entre a Geografia e a Literatura, evidencia-se o argumento de Araújo (2007, p. 24-25) quando indica que estas

[...] se entrecruzam como leituras possíveis de uma recriação imaginaria da realidade, que constroem e dão sentido ao mundo. Ao mesmo tempo em que se aproximam ficção e realidade, observam-se também suas diferenças e constatase que as narrativas literárias geográficas e históricas são formas diferentes de percepção do real.

Sem dúvida, uma reflexão sobre a representação do espaço é possível através deste encontro, pois esta análise leva em conta a percepção, a experiência vivida e adquirida pelo individuo, visando à compreensão sobre seu comportamento e sentimentos em relação a esse espaço, ou seja, o lugar.

Tuan (1982, p. 82) esclarece que "o lugar é aquele em que o indivíduo se encontra ambientado, no qual está integrado. Ele faz parte do seu mundo, dos sentimentos e 
afeições; é o centro de significância ou um foco de ação emocional do homem". Afirma que o espaço se torna lugar a partir do momento em que ele é "inteiramente familiar" e "à medida que adquire definição e significado", configura-se em "um mundo de significado organizado" (TUAN, 1983, p. 83, p.151, p. 198). Por isso, o espaço quando ganha significado para alguém em função de seu sentimento de identificação ou pertencimento para com o mesmo, transforma-se em lugar.

Neste mesmo caminho, Cavalcante e Nascimento (2009, p. 100) atestam esta questão ao afirmarem que "o espaço e o lugar onde uma pessoa reside estáo intimamente relacionados com sua maneira de ser, pois o lugar reflete as atitudes e condutas, emoçóes e sensações do homem. Laços afetivos com o espaço são uma das experiências mais intensas do homem". Na discussão sobre o espaço e simbolismo, Corrêa (2012, pp. 139-140) considera que existem dois tipos de lugares simbólicos identificando como vernaculares aqueles que são públicos "impregnados de tradiçóes populares locais e marcados por uma conexão identitária”, e que o lugar pode ter seu sentido simbólico construído não somente por seus próprios moradores, mas também por agentes externos, distinguindo-se assim em diversificação de simbolismos em uma mesma cidade, por exemplo.

No percurso para se compreender sobre identidade perpassa reconhecer que esta se constitui em um conceito em construção considerando as diferentes concepçóes, pontos de vista e aplicaçóes, além das diversas possibilidades relacionadas a partir do significado dado, seja social, cultural, étnica, espacial, territorial e muitas outras.

Por isso se fala tanto de identidades, mas que perspectiva enseja-se neste trabalho? Considerando identidade pela ótica de Silva (2014, p. 81) como produto resultante "de um processo de produção simbólica e discursiva" significando "demarcar fronteiras, fazer distinçôes entre o que fica dentro e o que fica fora” (SILVA, 2014, p. 82), organiza-se uma perspectiva que para a análise do texto literário em questáo, a identidade do autor está expressamente marcada pelo seu amor por seu estado de origem e sua dor pela saudade. Assim como se traduz, por exemplo, a identidade de gênero pela dinâmica biológica, as identidades nacionais são forjadas através de laços como a língua, brasóes e bandeiras, entre outros símbolos. Nesta discussão, Hobsbawn (2013) infere que para estabelecer a classificação de um povo enquanto nação importa considerar três critérios: o primeiro quando um povo está historicamente associado a um Estado existente ou um de passado recente e durável, levando-se a uma aceitação dessa condição; o segundo a partir da existência de uma elite cultural constituída há longa data e que detém um vernáculo administrativo e literário escrito, como por exemplo, a língua utilizada como elemento agregador de uma população; e o terceiro pela concreta capacidade de conquista, uma vez que a condiçáo do imperialismo leva a populaçáo a construir para si uma consciência coletiva enquanto povo.

Admite-se ainda uma identidade espacial consoante a forte relação que se pode desenvolver com um determinado espaço estabelecendo com ele uma conexão identitária. $\mathrm{Na}$ geografia então, este espaço identitário denomina-se na abordagem cultural de lugar.

Hall (2014) aponta que a identidade é muito mais do que sabermos quem somos e de onde viemos, mas principalmente sobre o que podermos nos tornar, como somos 
representados e como essa representação nos afeta. A relação afetiva com o lugar é também representacional, simbólica, pois depende da percepçáo, subjetividade e sentimento de cada um, variando de indivíduo para indivíduo, de grupo para grupo e muitas vezes significa justamente como queremos ser vistos ou como pensamos que somos vistos em relação a este lugar. Também está intrínseca uma relação de empoderamento a partir do momento que se expressa "meu lugar".

As identidades abarcam significativa relação de poder, sendo nas palavras de Hall (2014, p.112) "pontos de apego temporário às posiçôes-de-sujeito" construídos pelas práticas dos discursos. Isto é, o fluxo do discurso respondendo ao que se espera sobre o que pensam sobre nós, nos impulsiona a estabelecer mesmo que provisoriamente, a nossa identidade. Este aspecto pode ser apoio para se afirmar o caráter não fixo, não permanente da identidade, em processo de construção constante.

Infere então Haesbaert (1999, p.175) que "determinadas identidades ou, [...] facetas de uma identidade, manifestam-se em função das condições espaço-temporais em que o grupo está inserido", buscando o reconhecimento e afirmação no encontro ou embate com o Outro, muitas vezes em um diálogo difícil e conflituoso. Trabalha com a perspectiva de uma identidade socioterritorial quando os aspectos inerentes para estruturação da identidade social relacionam-se a um território ou parte dele, tanto de forma concreta como simbólica. Deste modo, afirma ainda que as "as identidades se situam frente ou num espaço simbólico, social / historicamente produzido" (HAESBAERT, 1999, p. 179).

Hall (2005, p.71-72) sobre essa dimensão simbólica afirma que “[...] todas as identidades estão localizadas no tempo e no espaço simbólico. Elas têm [...] "geografias imaginárias" [...]; suas "paisagens" características, seu senso de "lugar", de casa / lar [...], bem como de localizaçóes no tempo - nas tradições inventadas [...]". Essas "geografias imaginárias" de que trata Hall (2005) pode agregar as representaçóes que o espaço enseja para cada ser humano ou para um grupo social a partir de diferentes símbolos ou outras formas de manifestação cultural.

Como inserir neste contexto a produção literária? Seguramente enquanto produto da cultura humana os romances, contos e poesias são reflexos, representações dos pensamentos e sentimentos dos sujeitos que os elaboram. Sendo assim, através da análise de seus conteúdos, de seus discursos é possível inferir diferentes dimensóes pertinentes à natureza humana, dentre elas sobre a identidade.

Cavalcante e Nascimento (2009, p.102) afirmam que "a literatura, assim como os estudos de geografia, situa o homem em um espaço definido, caracterizando sua cultura, sua organização social e política, sua história; enfim, definindo-o enquanto sujeito atuante, consciente e transformador", enfatizando ainda uma relação com a geografia regional. Neste sentido analisam que "considerando a literatura como um documento revelador da subjetividade de uma determinada região, pode-se relacioná-la à geografia regional”. Acrescentam ainda em sua análise que "o espaço, em muitas obras literárias regionais, constitui a sua própria razão de ser” e que a literatura regional no Brasil se constitui em um exemplo em função das peculiaridades das características de cada região do país. Portanto, para os autores 
A literatura reflete a sensibilidade humana, apresenta-nos outros tempos, as estruturas sociais, as ideologias, os anseios espirituais e as indagaçóes filosóficas, envolvendo o leitor na ambiência de cada época, de cada espaço e lugar. A literatura regional vai além da utilização de determinado espaço geográfico, vai além da expressão da cor local ou da utilização de temas rurais (CAVALCANTE; NASCIMENTO, 2009, p. 102).

Este último aspecto entende-se ser pertinente nesta discussão considerando o objeto de estudo que traz, à luz de uma análise da geografia cultural, os "ecos do coraçáo"2 de um poeta expressos em uma obra da literatura regional e piauiense.

\section{O POETA DA LIRA: NOTAS BIOGRÁFICAS}

Piauiense, natural de Barras ${ }^{3}$, o poeta Hermínio Castelo Branco teve uma curta vida e produção literária morrendo aos 38 anos, deixando como legado somente uma obra "Lira Sertaneja", publicada originalmente sob o título de "Ecos do Coraçáo" em 1881. Sua infância foi envolvida em brincadeiras típicas sertanejas, mas aos dezoito anos alistou-se no exército para lutar pela pátria na Guerra do Paraguai. Dessa maneira, viveu a maior parte de sua vida fora do Piauí, pois no exército serviu principalmente na região norte. No entanto quando se sentiu doente retornou ao Piauí, para a capital Teresina, vindo a falecer em 1889.

$\mathrm{Na}$ escrita de seus apontamentos biográficos sobre Hermínio Castelo Branco, o padre e historiador piauiense Joaquim Chaves (1994, p. 137) registra o amor que o poeta tinha pela vida agreste e sertaneja afirmando que "o de que ele gostava era mesmo da natureza, da vida do campo, da roça, do contato com o povo rústico do sertáo, assimilando-lhe a vida, o linguajar, os costumes", vivendo mesmo como vaqueiro e caçador. Neste contexto destaca inclusive que essa escolha do poeta para os piauienses "em vez de um mal foi um bem", pois sem essa escolha a obra "Lira Sertaneja" náo existiria como o que chamou de um monumento "da poesia nativa, original, autêntica, sem artifícios, e que retrata fielmente os costumes e o linguajar do sertanejo do Piauî" na época de sua escrita (CHAVES, 1994, p.138).

Pinheiro Filho (2010, p.14), no prefácio que escreveu para a décima edição da obra publicada em 1972 e reproduzido na décima primeira edição de 2010, como parte da coleção Grandes Textos organizada pela Academia Piauiense de Letras e utilizada neste trabalho, indica que o poeta "era exclusivista" e "só os cenários e as cenas de sua infância e juventude delimitaram os temas de sua poesia”. Registra ainda que Hermínio Castelo Branco era

[...] arraigado e sinceramente convicto de que o mundo devia parar, a fim de se conservassem imutáveis os cenários que amava, tanto humanos como geográficos, seria capaz até de ultrapassar as raias da lei, para conseguir seu intento [...] Não

Referência ao título original da obra que se traduz fielmente nos versos da poesia de Hermínio Castelo Branco.

O poeta nasceu em 20 de maio de 1851 em uma fazenda denominada Chapada da Limpeza pertencente na época ao município de Barras, hoje fazendo parte do município de Esperantina (CHAVES, 1994). 
podendo frear o mundo, desejava ao menos que, em volta de seu céu na terra, nada se modificasse, cerrando os olhos para que ficasse além (PINHEIRO FILHO, 2010, p. 17).

As circunstâncias fizeram com que o poeta se afastasse do seu estado natal por quase toda sua vida, mas o espaço piauiense e os costumes sertanejos sempre estiveram presentes no seu cotidiano, refletindo-se em seus versos, como corrobora Miranda (2006, p. 2) ao afirmar que:

Embora sendo obrigado a viver grande parte de sua curta vida fora do Piauí, Hermínio Castelo Branco foi, entre nós, o mais fiel intérprete da alma nordestina, descrevendo com rara competência e exatidão o modus vivendi sertanejo, pintando quadros com a precisão de um grande artista do verso (MIRANDA, 2006, p. 2).

Deste modo, Hermínio Castelo Branco se configura como um poeta cujo amor ao seu lugar é extremoso e sólido, e sua poesia retrata claramente esse lugar, tanto nos aspectos fisiográficos, descrevendo as planícies, rios e matas (vegetação), como em relação aos costumes e tradiçóes locais como, por exemplo, a farinhada, festa de São Gonçalo, entre outras, enaltecendo ainda a figura do vaqueiro, personagem constante em seus poemas e componente da identidade nordestina e também piauiense.

\section{O PIAUÍ NA POESIA DE HERMÍNIO CASTELO BRANCO: IDENTIDADES, ESPAÇO E LUGAR}

No livro "Lira Sertaneja” o poeta piauiense reconhece-se enquanto parte de seu espaço tipicamente piauiense / sertanejo enlevando em suas poesias náo somente os aspectos naturais da paisagem local, mas também os produtos das tradiçóes culturais de sua gente. Tendo escrito essa única obra, mas republicando-a várias vezes com acréscimo de poemas e melhorias, em sua opinião da escrita dos já existentes, Hermínio, demonstra estar em busca de uma identidade própria arraigada a sua origem, mas que se processa gradualmente. Hall (2005, p. 38) assinala que "a identidade é realmente algo formado, ao longo do tempo, através de processos inconscientes, e não algo inato, existente na consciência no momento do nascimento".

Poemas como "O Vaqueiro do Piauî" e "Canto do Desterrado", respectivamente a primeira e a última da obra, destacam a autoafirmação do poeta enquanto piauiense / sertanejo, aqui lhe conferindo uma identidade pessoal, encerrando com um lamento saudoso de sua terra natal, confluindo na identidade espacial. Este último poema também possibilitaria a inferência a uma identidade nacional, uma vez que o discurso traz alusão muitas vezes à pátria e sua importância para o autor.

$\mathrm{Na}$ análise dos poemas de Hermínio Castelo Branco procurou-se identificar palavras que pudessem expressar as ideias do autor e deste modo inferir sua relação ou conexão identitária com sua terra, seu espaço, seu lugar, o Piauí. Não se configurou uma tarefa difícil, uma vez que toda a obra "Lira Sertaneja” está impregnada do sentimento do autor 
em relação a seu estado de origem. Palavras como: sertão (sertóes), ${ }^{4}$ Piauí, saudoso, terra querida, memória, saudosa(s), saudosa despedida, saudosa terra, saudade e pátria tão distante funcionam como totens desta identidade sertaneja / piauiense do poeta cantador e aparecem negritadas nas estrofes dos poemas reproduzidos para facilitar sua identificaçáo. Dentre estas, as palavras sertão e saudade são as que mais se repetem, estando intrinsecamente relacionadas ao âmago do poeta e à sua relação identitária com o Piauí.

Logo na primeira estrofe de "O Vaqueiro do Piauí" o poeta expressa claramente que ele é um sertanejo rude que só fala a língua das selvas, isto é, não tem refinamento é do povo. No decorrer deste e de outros poemas está sempre se reconhecendo como poeta cantador de seu povo, de seus costumes, empregando uma linguagem típica do sertanejo com muitas expressóes ou termos próprios.

Eu sou rude Sertanejo:

Só falo a língua das selvas

Onde impera a natureza

Não sei fazer epopeias,

Não entendo de poemas,

Nem choramingo pobreza.

$[\ldots]$

E quem não for sertanejo,

E queira compreender

A beleza de expressão,

Consulte dicionários

Da língua chã, verdadeira,

Do homem cá do sertão.

$[\ldots]$

Nos sertóes onde nasci,

$\mathrm{Na}$ viola temperada

Cantei a glória passada

Dos campos do Piauí.

(O Vaqueiro do Piauí - Hermínio Castelo Branco, 2010. p. 29, 47).

Em outros poemas o ufanismo ao sertão, seu sertão como melhor lugar, o mais aprazível, o mais belo, o "paraíso", apresentando caraterísticas singulares está muito presente como demonstram os trechos a seguir, indicando sua estreita relação com seu espaço geográfico.

4 Em seus poemas Hermínio Castelo Branco se refere ao sertão do interior do Piauí no qual está inserido o local onde nasceu e viveu sua infância, também denominado sertóes de dentro (NUNES, 1981; ABREU, 1998). 
[...] E quando os raios dourados

Do astro-rei fulgoroso,

Lá no meu sertão saudoso

Purpurizam lindos prazos;

$[\ldots]$

Enfim, quando a natureza

Ostenta maior beleza,

Que só se vê no sertão.

(São Gonçalo nos Sertóes - Hermínio Castelo Branco, 2010. p. 123).

Caro leitor! Algum dia

Viajaste nos sertóes

Do meu belo Piauí?

[...]

Ora, leitor, se eu não fosse

Também filho do sertão,

Estranhando o sertanejo

E sua boa intenção

Ficaria encalistrado,

Com o pobre homem zangado.

(Recordações de viagem - Hermínio Castelo Branco, 2010. p. 147, p.154)

Deslizava o mês de agosto,

Numa tarde prazenteira,

Que só se vê no sertão;

[...]

Depois tudo se acalmou:

$\mathrm{O}$ vento mais não soprava,

Nem a coruja piava,

Nenhum ramo balançou!

É nessa hora que o mundo,

Entre o silencio profundo,

Me parece um paraíso...

É no centro do sertáo

Que me pulsa o coração,

Que ventura só diviso!

(Luar de Agosto (Cena de Caçada) - Hermínio Castelo Branco, 2010. p. 176, p. 181) 
O diálogo com o leitor também se traduz em uma autoafirmação, pois o reconhecimento do Outro sobre quem somos é normalmente relevante para a construção da identidade de uma pessoa. Para ele, enfatizar suas impressóes para o leitor é compartilhar com ele seus sentimentos e afliçôes. Fazer dele tanto sua testemunha, como seu cúmplice.

É possível verificar no poema "Em Viagem ao Amazonas" que a saída de sua terra o obriga a romper os que ele denomina de "laços mais doces", indicando que para ele a relação que mantem com sua terra natal é delicada e suave, mas forte e sólida.

Retirando-me saudoso,

De minha terra querida,

Rompendo os laços mais doces

(Se há doçuras na vida),

Vou desferir neste canto

De saudosa despedida.

(Em Viagem ao Amazonas - Hermínio Castelo Branco, 2010. p. 235)

Outros trechos relatam sobre sua vida enfatizando que nem as alegrias nem tristezas o farão esquecer sua terra, ressaltando as belezas do espaço geográfico no qual passou sua infância, brincando em harmonia com a natureza, sendo capaz até de sentir o "choro" dos riachos.

Porém tu, fado inconstante,

Que és a trena da vida,

Que sorris quando soluça

De dor, minh'alma transida,

Não me farás esquecer

De minha terra querida.

Das verdejantes florestas,

Onde a infância passei;

Das campinas matizadas,

Onde de tarde brinquei,

E dos humildes regatos,

Cujos gemidos notei.

(Em Viagem ao Amazonas - Hermínio Castelo Branco, 2010. p. 235)

Hermínio afoga suas mágoas em relação à saudade de sua terra através de seu "canto poético" em sua "lira sertaneja", 5 companheira em suas horas de doce melancolia, como traceja nas seguintes estrofes:

\footnotetext{
5 A lira é um instrumento musical de cordas que no caso do nordestino assemelha-se a um violão. Como se considerava um poeta cantador o autor mudou o título original do seu livro para "Lira Sertaneja" justamente em alusão a utilização deste instrumento como testemunha de seus sentimentos e angústias expressado muitas vezes em seus poemas.
} 
De tudo, sim, quanto guardo

No meu triste coração,

Afagarei na memória

Imortal recordação...

E nas cordas desta lira

Acharei consolação.

E quando, saudosa terra,

Dos mares não te avistar;

Quando o sol no seu zênite (Sic)

Nas ondas se mergulhar,

Te enviarei um suspiro

Pela brisa que passar.

(Em Viagem ao Amazonas - Hermínio Castelo Branco, 2010. p. 236)

No poema "À Margem do Rio Negro", o único de sua obra que não tem o espaço piauiense como objeto de descrição, mas o tem de forma abstrata como uma saudade pungente, que o entristece e o deixa sem poder cantar com a lira, como demonstram os versos seguintes.

[...] Aqui passam as águas preguiçosas,

Certamente fatigadas da viagem.

Assim como na estrada desta vida

Eu faleço de cansaço, sem coragem...

Com elas nas areias se deslizam,

E no declive do rio vão descendo,

Eu também dos meus lares desprendi-me,

A força do destino obedecendo.

Como as águas murmurantes e saudosas,

Pelas praias longos beijos atirando,

Minhas áureas esperanças me deixaram,

Contigo, ó terna lira, soluçando.

Basta! Basta! Companheira de martírios!

Quem nos bosques cantava alegremente

Hoje, triste, da pátria táo distante,

Sucumbe de saudade, a mais pungente.

(À Margem do Rio Negro - Hermínio Castelo Branco, 2010. pp. 239-240) 
Através do poema "Canto do Desterrado", reproduzido na íntegra dada a sua relevância para identificação da conexão identitária do poeta com sua terra natal, com seu espaço, com seu lugar, é possível observar que além da descrição física das paisagens locais, nas quais o autor viveu em sua infância, demonstra ainda a falta que ela lhe faz com uma presença marcante da palavra saudade em praticamente todas as estrofes.

Qual é o ente que longe

Do torrão onde nasceu,

Desterrado no estranho,

Não se recorda do seu?

A distância é importante

Para quem saudades sente.

Tenho saudades dos bosques,

Das brenhas virgens, sombrias,

Dos tabocais intricados,

Entre as vertentes mais frias,

Dos campos tenho saudades,

Onde eu brincava de tarde.

Tenho saudades das fontes,

Dos olhos-d'água vitais,

Das lagoas pitorescas

Das cascatas naturais

E da sombra hospitaleira

Da soberba gameleira.

Tenho saudade das noites,

Em que passei atilado,

Sobre ramos de pau-d'arco,

Suavemente embalado

Sob um luar prazenteiro,

Esperando o capoeiro.

Tenho saudades do ronco

Que fazia o tambori.

E do queixoso carpido

Da queixosa juriti;

Tenho saudades, também,

Do vigilante quenquém. 
Dos mundéus tenho saudades

Nas veredas dos tatus

E dos laços que armava

Para colher as nambus

Tenho saudosa memória

Do cantar da sericória.

Tenho saudades do grito

Retumbante da acauá,

Sobre o atalho do morro,

Pousada pela manhã.

E da funerária risada

Da mãe-de-lua, chamada.

E da temida raposa

Da chapada das Mangabeiras,

E velozes caititus

Das matas das Cabeceiras,

E do macaco ladrão

Das roças do Batalhão.

Enfim, eu tenho saudades

De todo meu Piauí:

Prefiro enterrar-me lá,

A ser imortal aqui

E confio em Deus bondoso

De ser ainda ditoso.

(Canto do Desterrado - Hermínio Castelo Branco, pp. 243-244)

Infere-se então que essa repetição da palavra saudade no poema exacerba o sentimento do poeta e demonstra sua necessidade de afirmar que através da saudade ele estará sempre conectado com sua terra, com seu lugar, reafirmando sua conexão identitária. No poema ele relembra passagens de sua infância sempre se relacionando a um determinado elemento da paisagem natural local como os bosques, as vertentes, fontes e olhos d'água, lagoas e cascatas, e até às plantas e animais típicos de sua região. Entretanto, destaca-se a derradeira estrofe, pois em suas últimas palavras deixa claro que prefere morrer no Piauí a ser imortal em qualquer outro lugar.

Assim, é evidente o entendimento sobre diferentes identidades que a poesia de Hermínio Castelo Branco pode apresentar. Enfatiza-se, entretanto a que se relaciona com seu espaço de origem, seu lugar, a luz da abordagem da geografia cultural emoldurado pelo desejo do autor de que os aspectos do lugar, fisiográficos ou náo, permaneçam da 
mesma forma que em sua memória. A poesia teria essa função: imortalizar um sentimento de pertencimento, o amor ao seu lugar, a sua identidade com o Piauí.

A análise dos poemas da "Lira Sertaneja" de Hermínio Castelo Branco possibilitou reconhecer a conexão identitária de seu autor com o espaço presente em sua narrativa poética, no caso o Piauí. Castells (2006, p.22) entende "por identidade a fonte de significado e experiência de um povo", e estes elementos estão enraizados nos poemas de Hermínio Castelo Branco, uma vez que constrói para si uma significativa relação com o seu espaço, através de suas experiências com a natureza e com as tradiçóes culturais e sociais de seu povo, narradas em vários de seus poemas.

Deste modo, a identidade pode ser expressa através do sentimento de pertencimento a um grupo ou a um lugar. As referências sociais e culturais de onde se vive e com quem se vive deixam marcas que no decorrer do tempo contribuem para a construção de uma conexão identitária. Os poemas analisados são exemplos desta relação de identidade com o espaço / território / lugar que possibilitou a identificaçáo de múltiplas identidades: cultural, espacial e territorial. No entanto, o espaço geográfico do Piauí, representado notadamente pelo sertão, impregna nos versos de Hermínio Castelo Branco sua vigorosa identidade piauiense.

\section{CONSIDERAÇÓES FINAIS}

A Geografia Cultural em seu estudo das manifestaçóes humanas culturais sobre os espaços permite reconhecer diferentes vertentes de análise, utilizando dentre outras ferramentas, o texto literário em forma de poesia.

Nas inferências da abordagem cultural, um aspecto também se sobressai quando se trata de reconhecer a relaçáo do ser humano com seu espaço: a identidade. Identidade essa, cuja construção perpassa por diferentes caminhos, nem sempre podendo ser definitiva, mas geralmente decorrente de variadas influências.

A poesia de Hermínio Castelo Branco analisada neste trabalho registra lembranças e memórias impregnadas de tristeza e saudade de sua terra natal inferindo ao poeta uma forte relação identitária com o Piauí, tanto no sentido espacial, como cultural. Inseridas no final do livro "Lira Sertaneja" na sequência, os poemas "Em Viagem ao Amazonas", "À Margem do Rio Negro" e "Canto do Desterrado" ensejam uma identidade piauiense do autor relacionada principalmente ao amor à sua terra natal, às suas paisagens e elementos naturais, ao ponto de ele preferir morrer no Piauí a ser imortal longe dele. 


\section{REFERÊNCIAS BIBLIOGRÁFICAS}

ABREU, Capistrano de. Capítulos de História Colonial: 1500-1800. Brasília: Senado Federal, 1998. 226 p. (Biblioteca básica brasileira)

ANDRADE, Manuel Correia de. A terra e o homem no Nordeste: Contribuição ao Estudo da Questão Agrária no Nordeste. 6. ed. Recife: UFPE, 1998. 305p.

ALMEIDA, Maria Geralda de. A geógrafa: Linguagem geográfica e Literatura. In: PINHEIRO, Robinson Santos. Geografia e literatura: diálogo em torno da identidade territorial sul-mato-grossense. Dourados: UFGD, 2014. pp.17-19.

ALMEIDA, Maria Geralda de. Os Cantos e Encantamentos de uma Geografia Sertaneja de Patativa do Assaré. In: MARANDOLA JR., Eduardo; GRATÃO, Lúcia Helena Batista (Orgs.). Geografia e Literatura: Ensaios sobre geograficidade, poética e imaginação. Londrina, EDUEL, 2010. pp.141-165.

APPOLINÁRIO, Fábio. Dicionário de metodologia científica: um guia para a produção do conhecimento científico. São Paulo: Atlas, 2009.

ARAÚJO, Heloísa Araújo de. Geografia e literatura: um elo entre o presente e o passado no Pelourinho. Salvador, 2007. 152f. Dissertação (Mestrado). - Pós-Graduação em Geografia. Instituto de Geociências. Universidade Federal da Bahia, 2007.

BERQUE, Augustin. Paisagem-Marca, Paisagem-Matriz: Elementos da Problemática para uma Geografia Cultural. In: ROSENDAHL, Zeny; CORREA, Roberto Lobato. (Orgs.). Paisagem, Tempo e Cultura. Rio de Janeiro: EdUERJ, 1998. pp. 84-91.

CASTELLS, Manuel. O Poder da Identidade. 5. ed. São Paulo: Paz e Terra, 2006. (A Era da Informação: Economia Sociedade e Cultura, 2).

CASTELO BRANCO, Hermínio. Lira Sertaneja. 12. ed. Teresina: APL; FUNDAC; DETRAN, 2010.

CAVALCANTE, Maria Imaculada; NASCIMENTO, Lívia Abrahão do. Literatura e Geografia: uma abordagem do espaço em "A mulher que comeu o amante". Espaço em Revista, v. 11, n. 1, pp. 99-115, jan/jun. 2009.

CHAVES, Joaquim Raimundo Ferreira. Apontamentos biográficos e outros. Teresina Fundação Cultural Monsenhor Chaves, 1994. 250p.

CLAVAL, Paul. As Abordagens da Geografia Cultural. In: CASTRO, Iná Elias de; GOMES, GOMES, Paulo Cesar da Costa; CORRÊA, Roberto Lobato. (Orgs.). Exploraçóes geográficas: percursos no fim do Século. Rio de Janeiro: Bertrand Brasil, 1997. pp. 89-117.

CLAVAL, Paul. O papel da Nova Geografia Cultural na compreensão da ação humana. In: ROSENDAHL, Zeny; CORREAA, Roberto Lobato. (Orgs.). Matrizes da Geografia Cultural. Rio de Janeiro: EdUERJ, 2001. pp. 35-86.

CORRÊA, Roberto Lobato. Espaço e Simbolismo. In: CASTRO, Iná Elias de; GOMES, Paulo Cesar da Costa; CORREA, Roberto Lobato (Orgs.). Olhares geográficos: modos de 
ver e viver o espaço. Rio de Janeiro: Bertrand Brasil, 2012. pp.133-153.

CORRÊA, Roberto Lobato. Geografia Cultural: Passado e Futuro - Uma introdução. In: ROSENDAHL, Zeny; CORREAA, Roberto Lobato (Orgs.). Manifestaçóes da cultura no espaço. Rio de Janeiro: EdUERJ, 1999. pp. 49-58.

FERREIRA, Luís Felipe. Acepçóes Recentes do Conceito de Lugar e sua Importância para o Mundo Contemporâneo. Revista Território, Rio de Janeiro, Ano V, n. 9, jul./dez. de 2000.

HALL, Stuart. A identidade cultural na pós-modernidade. Tradução de Tomaz Tadeu da Silva e Guacira Lopes Louro. 10. ed. Rio de Janeiro: DP \& A, 2005. 104p.

HALL, Stuart. Quem precisa de identidade? In: SILVA, Tomaz Tadeu da (Org.). Identidade e diferença: A perspectiva dos Estudos Culturais. 15. ed. Petrópolis: Vozes, 2014. pp.102-133.

HAESBAERT, Rogério. Identidades territoriais. In: ROSENDAHL, Zeny; CORREA, Roberto Lobato (Orgs.). Manifestaçóes da cultura no espaço. Rio de Janeiro: EdUERJ, 1999. pp.169-190.

HOBSBAWM, Eric. Naçóes e nacionalismo desde 1780: Programa, mito e realidade. Tradução de Maria Celia Paoli e Anna Maria Quirino. 6. ed. Sáo Paulo: Paz e Terra, 2013.

LIMA Angelita Pereira de; ARAÚJO, Fernando Moreira; SALGADO, Tatiana Rodrigues. Paisagem: A “Janela da Alma” da Geografia. In: SIMPÓSIO REGIONAL DE GEOGRAFIA - EREGEO, 11. Campos Jataí/GO, Anais... Campos Jataí/GO: UFG, 04 a 07 de setembro, 2009. pp.734-739.

McDOWELL, Linda. A transformação da geografia cultural. In: GREGORY, Derek; MARTIN, Ron; SMITH, Graham (Orgs.). Geografia Humana: Sociedade, Espaço e Ciência Social. Tradução de Mylan Isaack. Rio de Janeiro: Jorge Zahar Editor, 1996. pp.159-188.

MIRANDA, Reginaldo. Hermínio Castelo Branco - Intérprete da Alma Nordestina. Jornal Meio Norte, coluna Presença da Academia, ediçóes de 10 e 17 nov. 2006. Disponível em: http://www.academiapiauiensedeletras.org.br/notcom.asp?id=612\&categ=artigos. Acesso em: 20 fev. 2017.

NUNES, Odilon. Depoimentos Históricos. Teresina: COMEPI, 1981. 140p.

OLANDA, Diva Aparecida Machado; ALMEIDA, Maria Geralda de. A geografia e a literatura: uma reflexão. Geosul, Florianópolis, v. 23, n. 46, pp. 7-32, jul./dez. 2008.

PINHEIRO FILHO, Celso. Á guisa de prefácio e biografia. In: CASTELO BRANCO, Hermínio. Lira Sertaneja. 12. ed. Teresina: APL; FUNDAC; DETRAN, 2010. pp.7-19.

SÁ-SILVA, Jackson Ronie; ALMEIDA, Cristóvão Domingos de; GUINDANI; Joel Felipe. Pesquisa documental: pistas teóricas e metodológicas. Revista Brasileira de História \& Ciências Sociais, Ano 1, n 1. São Leopoldo (RS): Universidade do Vale do Rio dos Sinos UNISINOS, pp. 1-15, jul. 2009.

SILVA, Amenair Moreira; SANTOS, Edinúsia Moreira Carneiro; MARTINS, Sandra Regina. A Geografia através da Literatura: duas abordagens do Romance "Corta Braço". Cadernos de Geociências, v. 6, pp. 1-8, 2001. 
SILVA, Cristiane Rocha; GOBBI, Beatriz Christo; SIMÃO, Ana Adalgisa. Uso da análise de conteúdo como uma ferramenta para a pesquisa qualitativa: descrição e aplicação do método. Organizaçóes Rurais \& Agroindustriais, Lavras, v. 7, n. 1, pp. 70-81, 2005.

SILVA, Tomaz Tadeu da. A produçáo social da identidade e da diferença. In: SILVA, Tomaz Tadeu da (Org.). Identidade e diferença: A perspectiva dos Estudos Culturais. 15. ed. Petrópolis: Vozes, 2014. pp. 73-102.

TUAN, Yi-Fu. Espaço e Lugar: a perspectiva da experiência. Tradução de Lívia de Oliveira. São Paulo: DIFEL, 1983. 250p.

TUAN, Yi-Fu. Geografia Humanística. In: CHRISTOFOLETTI, A. (Org.). Perspectivas da Geografia. 2. ed. São Paulo: DIFEL, 1982. pp. 143-164.

Recebido em junho de 2017. Aprovado em dezembro de 2017. 